\title{
Research on the Application of Sponge City Concept in Trivanderlang's Landscape Design
}

\author{
Shebina Hussain \\ Department of Architecture, TKM College of Engineering, Kollam, India \\ shebinahussain1995@gmail.com
}

\begin{abstract}
With the process of urbanization, a lot of cities are faced with various environmental problems, many of which are associated with stormwater. To deal with these problems, Stormwater management in urban areas needs to incorporate new sustainable development concepts, and one of them is the concept of sponge city. The aim of this new concept is to create a city that absorbs rainfall and releases rainwater when required - similar to a sponge. In Trivandrum, urban floods take place because drainages are not available or are poorly built or have been blocked by disposed municipal waste and eroded soil materials. Urban waterlogging in Trivandrum occurs 3 to 6 times during monsoon with water depth of 0.6 to $1.2 \mathrm{~m}$, and persists for 2 to 24 hours in the central part and 3 to 4 days in the southern part of the city. For the development of a sustainable city, water management takes a major role to mitigating the water problems in Trivandrum through the sponge city concept.
\end{abstract}

Keywords: LID techniques, Sponge City Concept, Stormwater management, Urban Flooding

\section{Introduction}

Water logging in urban areas is widely reported from India and other countries. Most of the cities by virtue of their location in the coast or along the river are prone to water logging during monsoon months. Open space and spill area to accommodate excess water during monsoon months within the cities are fast diminishing due to growth of urbanization. At the same time there is generation of high surface run off on account of increase in surfaced area. This has resulted in growing susceptibility of urban centers for water logging. The creation of sustainable environment in urban area requires adequate viable solutions to address the problems like water logging, which affects urban infrastructure, mobility, overall urban environment and the quality of life of its people.

Undulated topography, ridge valley arrangements and presence of a main river, Karamana and several streams provided Trivandrum city a well functional natural drainage disposal system, which, over the years, has been interrupted in several places due to wide spread human intervention. This has changed the physical hydrological condition to a large extent.

Water logging occurs in Trivandrum city even during rainy days with below average precipitation in contrast to earlier incidence of waterlogging mostly during high intensity monsoon rain. This implies that water logging is not a problem of cloud burst alone. There are several issues from land shaping to drainage blockage contributing to this scenario. It is now realized that waterlogging is more of a management problem and therefore warrants attention from urban governance point of view.

During last couple of decades frequent water logging tended to disturb regular activities of urban dwellers in Trivandrum city. Severe water logging during 2015 drew Government attention and 'Operation Anantha', an inter-departmental urban flood mitigation programme was launched to improve the drainage system and reduce water accumulation. The Smart City programme and 'Swachh Bharat' scheme also consider water logging as one of the issues for which proper attention is necessary.

This work tries to mitigate these problems through the concept of Sponge city which was successfully implemented in China. The concept and its related recommendation and practices will provide numerous opportunities to integrate ideas from Eco hydrology, climate change impact evaluation and planning, and consideration of prolonged social and environmental aspects, within the urban land-use planning process in the city. Sponge city concept can control the urban waterlogging and improve the quality of water in a sustainable way. This eco-friendly concept can improve the living standards socially, economically and environmentally.

[9] A Sponge City is defined as a city that acts similar to a sponge and has a high adaptability to environmental changes and natural disasters. A Sponge City is capable of absorbing, storing, allowing permeation of, and cleansing rainwater, and releasing stored water for reuse when needed.

[10] Generally, a Sponge City makes use of Low-impact development (LID) strategies. The goal is to create a highquality living environment and realize a balanced water circulation system through less expensive means.

\section{Sponge City Concept}

The concept of a Sponge City is macroscopic and abstract, and varying understandings may be present in different professional sectors. From a landscape architect's standpoint, one of the major aims of a Sponge City involves treating rainwater as a resource and saving sufficient space for water conservation when developing urban areas. Depending on the terrain, urban design professionals are encouraged to keep and plan more wetlands, lakes, and parks. Moreover, urbanization should avoid flood areas as 
much as possible. By reducing flooding, the safety of water resources can be better ensured (Wu, 2015).

Another major aim of Sponge City is to reduce surface runoff. If runoff can be reduced, non-point source pollution can be controlled. By managing runoff at the source, rainwater will infiltrate on site and contribute to groundwater recharge. Thus, according to $\mathrm{Wu}$ (2015), a Sponge City should be designed to achieve maximum stormwater infiltration.

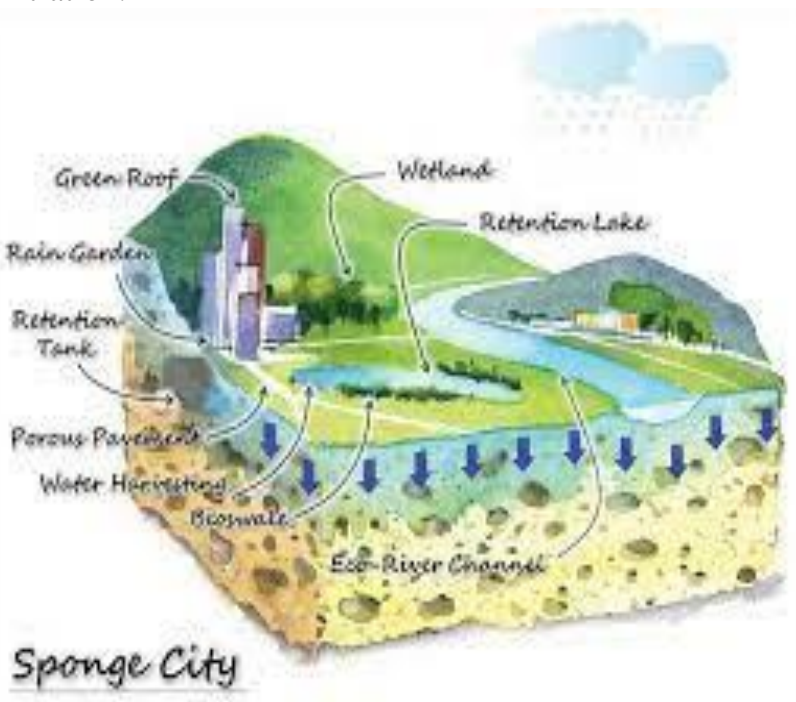

Figure 1: Schematic diagram of Sponge city

\section{Objectives and Scope}

The aim of the study is to mitigate urban flooding in Trivandrum city through the concept of sponge city.

- To understand the sponge city concept and identify the sponge parameters through literature reviews and case studies.

- To delineate the area and identify the existing issues \& potentials of the study area.

- To identify the applicability of sponge parameters in Trivandrum city by analysing the ground data using GIS.

- To formulate proposals and strategies and implementation plans to mitigate urban water logging.

The study will help to mitigate the urban water logging and helps to improve the liveability and sustainability of Trivandrum city region.

\section{Methodology}

The research will carry out in three stages, preparation \& collection of background materials, fieldwork \& site study and data analysis \& formulation of strategies. The major tasks in the first stage is to narrow down the research topic, read relevant academic materials, design the detailed research process, select appropriate methodologies, design interview question lists and a questionnaire.

In the second stage fieldwork is conducted. Major tasks in this stage are interviews, surveys, on-site observation in the city, and search for relevant secondary data from concerned authorities. The applicability of sponge parameters was identified by preparing thematic maps of geological and urban construction factors. Based on this a comprehensive vision for the study area has been formulate.

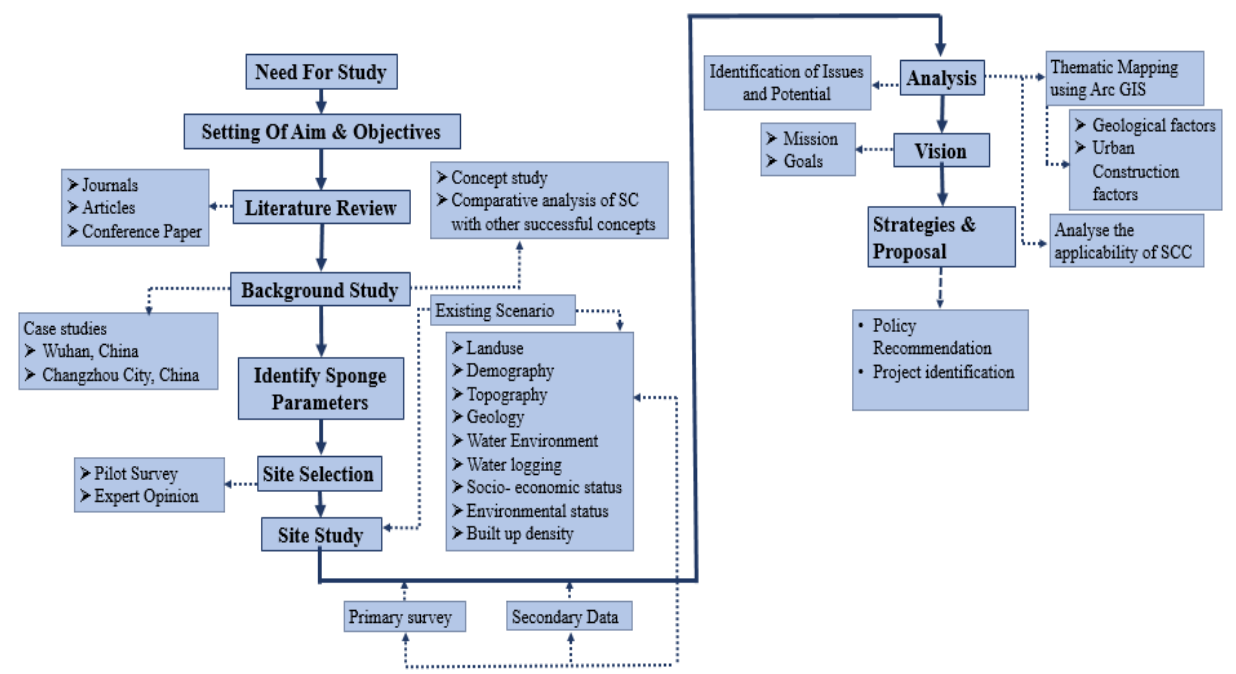

Figure 2: Methodology of the Study

\section{Study Area}

The study area is the urban area of Thiruvananthapuram (Trivandrum), Kerala State, India and its environs. Trivandrum is the capital city of Kerala State, India. Trivandrum with a population of about 957,730 (as per the 2011 census) situates between north latitudes $8^{\circ} 17^{\prime}$ and $8^{\circ} 54$ and east longitudes $76^{\circ} 41^{\prime}$ and $77^{\circ} 17^{\prime}$. Study area is delineated by considering the sponge parameters which are identified by studying the literature reviews and case studies. It mainly includes urban population density, building density, groundwater level, slope \& elevation details, vegetation density, drainage density etc. By analysing these data of Trivandrum corporation area and delineated the 
study area and also considering the priorities. Area delineated mainly on the basis of catchment area of important drains in the city. These drains have major role in urban flooding.

\subsection{Analysis of the Existing Status}

On analyzing the existing population density variation within the City it is seen that, there is a City core area with an average density of 7500 ppsq.km, a Central City area with an average density of only 4000 ppsq.km and an outer city area with an average density of only 3000 ppsq. km. Study area is having a gentle slope towards the central city $(<25 \%)$. It can be categorised as midland. The lowland area is dominated by alluvium, which are sandy loam to clayey loam in texture. The mid land soils are well drained laterite soils have a depth of less than $100 \mathrm{~cm}$ having dark reddish brown to red with gravelly clay loam to gravelly clay texture. The district has a climate that borders between tropical savanna climate and tropical monsoon climate.

Karamana River with two reservoirs at Peppara and Aruvikkara is the main surface water source for Thiruvananthapuram water supply scheme. The best-known tributary of the Karamana River is Killiyar. Domestic sewage discharge, increased surface run off from paved urban areas, urban effluents and waste dump in combination contribute to the deteriorating condition of the Karaman River and other surface water bodies draining the city. Impact of urbanization and human action are well evident. Deterioration of river water quality is a serious issue in the matter of source sustainability and it requires public action to ameliorate the situation.

$69 \%$ of residents surveyed have been raised their ground surface using Earth fill, concrete and other construction materials. Around $95 \%$ of height of the ground has been raised to about $40-60(\mathrm{~cm})$ and rest of $5 \%$ is about $60-80$ (cm). Some residential buildings have damages on floors and cracks on walls. Compound wall were collapsed. Dampness on walls and floors were found. Houses experience electric shock on walls. Houses built with mud blocks were collapsed and those with hollow concrete block shave dampness in a higher rate. After flooding paved surfaces were pulled out from floors. Water is stagnated in the road and mobility is severely affected. From the survey, water retained for 1 week in wards such as Palayam, Chalai area, fort, Vanchiyoor, Thampanoor, Valiyasala and Poonthura. It includes the main bus terminal and railway station. Flooding in this area occurs 3 to 6 times during monsoon with water depth of 0.6 to $1.2 \mathrm{~m}$, and persists for 2 to 24 hours in the central part and 3 to 4 days in the southern part of the city.

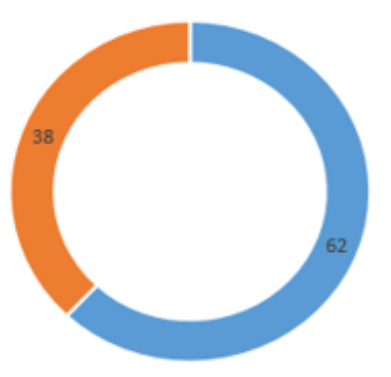

Data analysis of damage caused

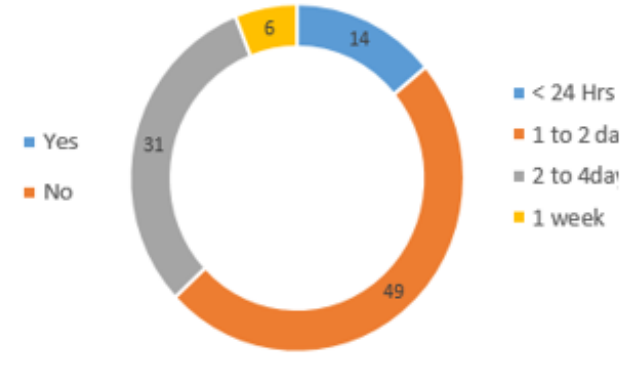

Data analysis of water retained

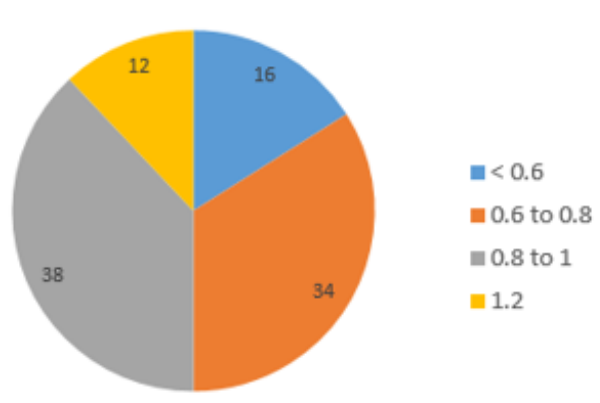

Data analysis of water level height

Figure 3: Flooding Details

\subsection{Drainage System}

The drainage network of the city consists of two rivers, a few canals (thodus), their feeders and lakes. The rivers are Karamana and Killiyar which flow through the city area. There are a number of drains and sub drains in the city area namely Pazhavangadi, Ulloor, Pattom, Kannanmoola (Amayizhanjan), Thekkenekara and Kariyil thodus and natural drains namely Tettiyar, Pangappara, KaimanamAzhamkulam, Amathara, Koori and Vattakkayal thodus. Other important drains contributing to storm water drainage to the TMC are Choozhampala, Anathanthodu, Edanada, Arayalloor ela and Thiruvallom-Pallathukadavu thodu. Water conservation is another important area that needs immediate attention. In spite of abundant water resources, the city is facing water scarcity. Hence conservation of water is needed to restore the water for future needs. The developing areas surrounding the city are witnessing large scale construction activities resulting in unscientific filling of low lying areas leading to blockage of natural drains and reduction in ground water recharge.

According to Census of India 2011, (District Census Handbook, Tinsukia) the Population of Ledo town is 11717. This population of Ledo are divided into certain category marginal workers, main workers, cultivators, agricultural labourers, other workers and non-workers, according to 2011 census. But here for this paper we are focusing on workers so marginal and main workers are considered. Since the study is focusing on the livelihood of women in Ledo coal mining area so, the women main and marginal workers are being taken for considering or analyzing the aspect of. In order to support the study on women livelihood a sample survey has been conducted in Ledo coal para area, which is near by the Ledo coal mine, to get the accurate result of the study. In this coal mine maximum number of people are engaged. 


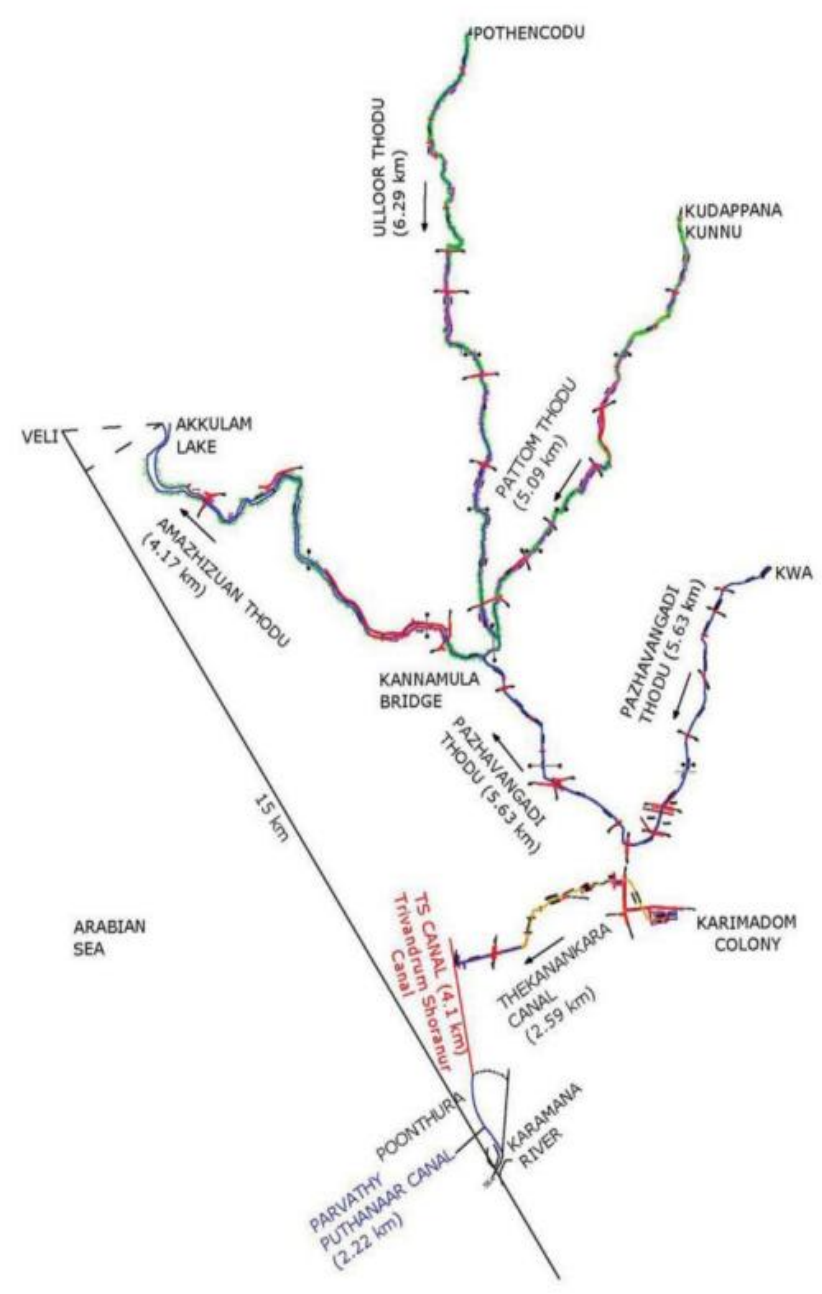

Figure 4: Drainage Network Trivandrum City

From Edavakode to Kannanmoola the Uloor thodu has a length of about $8 \mathrm{~km}$ and a width of 10 to $15 \mathrm{~m}$. Dhobis in the city used to wash cloths in this thodu. Some portion of thodu is noticed to be highly contaminated and the flow is stagnant in several reaches. Several natural drains join with this thodu bringing silt and debris to Kannamoola thodu. Due to solid wastes disposal and silt deposit inside the thodu the cross sectional area reduces leading to over flow of the thodu during rainy season resulting in flooding in the low lying areas on both sides of the thodu. Kannanmoola thodu also called Aamayizhanjan thodu starts at about $0.7 \mathrm{~km}$ upstream of Kannanmoola bridge. Before joining Akkulam lake Ulloor todu and Pattom thodu joins with Kannanmoola thodu. The Kannanmoola thodu has a width of 20 to $30 \mathrm{~m}$ and a length of about $5.7 \mathrm{~km}$. The Pazhavangadi thodu joins at about $0.25 \mathrm{~km}$ below the Ulloor and Pattom thodu confluence. As in the case of other canals in the city, Kannanmoola thodu is also in a very poor condition with low carrying capacity as a result of deposition of silt and debris, vegetation, poor maintenance, bank erosion and low velocity. Unless the condition is scientifically improved, possibility of flooding in this area cannot be controlled.

The Parvathy Puthanar is an artificial canal of $16.50 \mathrm{~km}$ length, stretching from Akkulam-Veli in the north to Kovalam in the south. The canal takes off from the Akkulam-Veli inlet and before ending up at Kovalam comes across a few openings to the sea, one of the important openings being Poonthurapozhi. On its path from AkkulamVeli to Kovalam, the Parvathy Puthanar canal is joined by the Karamana River. Before it reaches this opening, the Karamana River joins this waterway. The Akkulam-Veli system does not have a perennial river draining into it. The water from a small catchment of about $10 \mathrm{sq} \mathrm{km}$ joins the Akkulam wetland on its eastern side. Along with this, considerable wastewater is brought by the Ulloor canal. The mouth of Veli opens up by the natural processes for a short period, when the fresh water flow into the wetland is high during the monsoon. During this period, it behaves like a typical coastal estuary; mudflats get exposed at Akkulam during low tide.

\subsection{Flood Vulnerability Analysis}

All these raster layers are generated using Arc Hydro tools in Arc Map

Soil Map: Soil type and texture are very important factors in determining the water holding and infiltration characteristics of an area and consequently affect flood susceptibility. As a general rule, runoff from intense rainfall is likely to be more rapid and greater with clay soils than with sand

Slope: Land surface slope is one of the effective elements in floods. The danger from flash flood increases as the surface slope increases. It is a reliable indicator for flood susceptibility. The entire study area is sloping towards the centre of the city.

Runoff: Higher the runoff, lower the ground water recharge. Runoff is generated by comparing the landuse and soil map

Roughness: Surface roughness in terms of hydrodynamic friction is an essential input for flash flood simulation.

Using the formula, $\mathbf{Q}=\left(\mathbf{P}-\mathbf{I}_{\mathbf{a}}\right)^{\mathbf{2}} /\left(\mathbf{P}-\mathbf{I}_{\mathbf{a}}\right)+\mathbf{S}$

From the equation, curve number is generated. Reducing channel roughness results in faster stream velocities and less infiltration.

Drainage density: If the drainage network is dense at any area, it will be good indicator to high flow accumulation path and more likely to get flooded

Distance to Main Channel: Areas located close to the main channel and flow accumulation path are more likely to get flooded.

Land Cover: This describes the appearance of the landscape and is generally classified by the amount and type of vegetation, which is a reflection of its use, environment, cultivation and seasonal phenology. Land cover is other essential influences on runoff.

The AHP is a decision support tool, which is used to solve complex decision problems. 


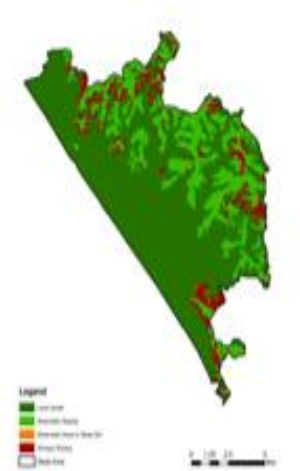

Slope map

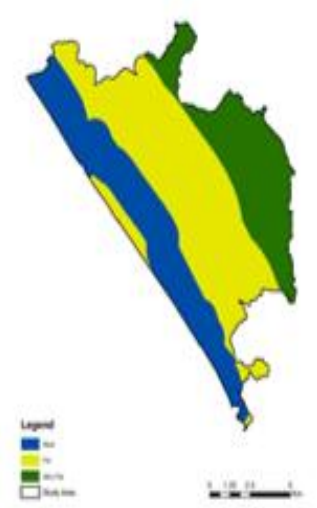

Distance to main channel map

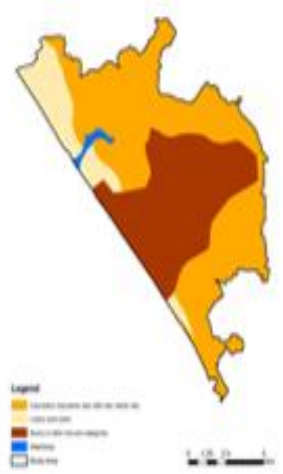

Soil map

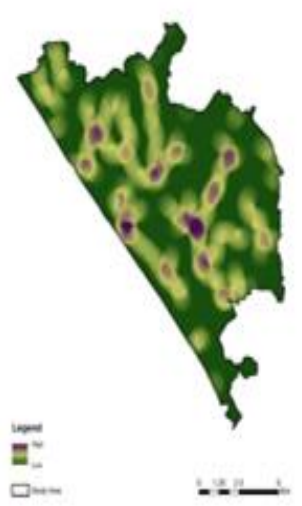

Drainage density map

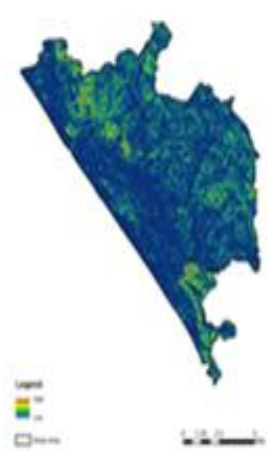

Roughness map

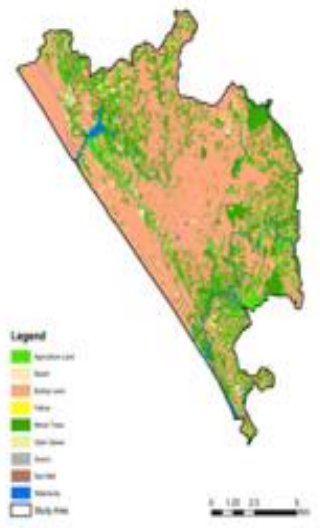

Landuse map

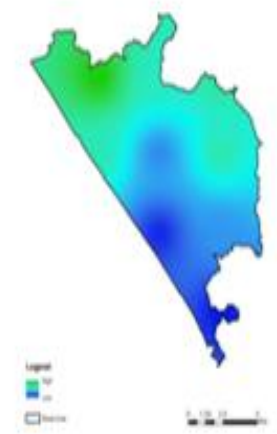

Runoff map

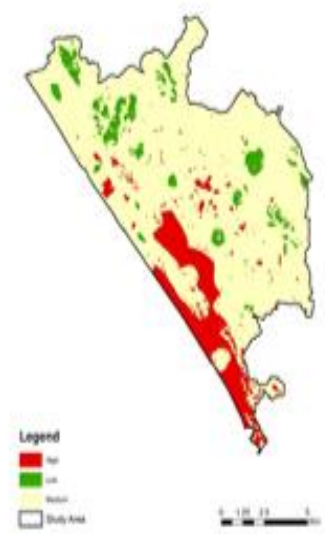

Flood Hazard map

Figure 5: Flood Hazard Mapping

From the Flood hazard map, it can be inferred that the low lying and highly urbanized areas of the city such as East fort, Thampanoor and South-west wards are prone to flood which is in agreement with the past flood events.

\subsection{Impact of Urbanization}

Due to the increase of population, landuse of the city has changed to a considerable extent. The ridges and slopes were occupied by roads and settlement and the valley bottoms were occupied by paddy fields. The settlement consists of garden houses. This was the situation from the origin of town till 1930's. In $190159.03 \%$ of the total area of the city was occupied by the paddy fields alone while the rest of the area were occupied by settlement and roads. The paddy fields extended along the river valley of Karamana river, Killi river and Parvathy Puthanar. It also extended from foot hill of the ridge in North to East Fort in the South along the present Bakery Junction, Rajaji Nagar and Thampanoor. In later decades, these paddy fields were encroached by settlement, road, railway and other commercial establishments as a result of which most of the surface are made impervious. Flood plains of Killi river and Karamana river are reclaimed and occupied by residential houses. Extensive reclamation of paddy fields for buildings is being carried on now in Medical college area, Kumarapuram, Kowdiar, Vattiyoorkavu, Poonthura and on either side of the railway in Karamana area. The depletion of paddy fields alone in the corporation area from 1901 To 1990 is Shown Below.

Table 2: Depletion of Paddy Fields

\begin{tabular}{|c|c|c|c|c|c|}
\hline Year & 1901 & 1961 & 1971 & 1981 & 1990 \\
\hline Total area of the city $\left(\mathrm{km}^{2}\right)$ & 25.6 & 44.58 & 74.93 & 74.43 & 74.93 \\
\hline Area under paddy fields $\left(\mathrm{km}^{2}\right)$ & 15.13 & 5.05 & 5.89 & 4.51 & 3.19 \\
\hline \% of total area & 59.03 & 11.31 & 7.86 & 6.02 & 4.26 \\
\hline
\end{tabular}

\section{Recommendations}

Entire area should be divided into different sectors and each sector should be providing with detention ponds of sufficient holding capacity with respect to the rainfall in the catchment which enable in ground water recharge. It can be any form recreational or water supply. An outlet drain should be connected to the major drain to drain out excess water.

Materials used for filling should be sandy soil as far as possible or at least top layers should be sandy. Filling should be compacted in layers of $10-20 \mathrm{~cm}$ to have uniform compaction by means of any compaction equipment.

Provide interceptors as recharge basins. First interceptor is Rajaji Nagar. Second interceptor is Manjalikulam ground. 


\section{Suggestions}

Regeneration of Ponds: The conversion of paddy fields and ponds into residential or commercial purpose creates more problems in the run off rain water. It's better to convert some areas into ponds which can act as either retention pond or detention pond. So by selecting the Manjalikulam ground, a part of putharikandam maidam is also made to pond and the remaining portion can be used for other purposes.

Bio- retention facility: These LID techniques used for increasing ground water recharge in low- lying areas

Green Roof: these green techniques can capture $45 \%$ of the actual rainfall. The collected water is also used for domestic purposes.

\section{Conclusion}

Due to the non-availability of land low lying areas are converting into built-up areas. The study reveals that both environment and development are essential for balance in nature and also there exists relation between surface drainage and conversion of low lying areas. The study reveals that change in landuse pattern especially in low lying areas of Trivandrum city, had led to adverse effects. Suitable remedial measures, that has to be adopted, at the policy level and implementation level is recommended in the study.

\section{References}

[1] Centre For Development Studies Case Of Thiruvananthapuram City, I. (Centre For Development Studies Case Of Thiruvananthapuram City, India). Centre For Development Studies Case Of Thiruvananthapuram City, India. Trivandrum: Centre For Development Studies.

[2] Department Of Town And Country Planning Government Of Kerala. (2011). District Urbanisation Report.

[3] Department Of Town And Country Planning. (2012). Thiruvananthapuram Masterplan. Trivandrum.

[4] Er. Shaheen Hassan, . (2020). Policies And Strategies For Flood Management:. Irrigation Design \& Research Board.

[5] Kerala State Land Use Board. (2013). Natural Resources Data Bank Thiruvananthapuram.

[6] Kerala State Pollution Control Board. (February 2019). Karamana River Action Plan. Trivandrum.

[7] S, S. J. (2017). Water Logging In Parts Of Thiruvananthapuram City And An Overview of 'Operation Anantha'. Trivandrum: Centre For Development Studies .

[8] Sourav K. Biswas, P. R. (2019). The Sponge Handbook : Chennai.

[9] Wu, Y. (. (2015). Sponge City Design: Concept, Technology \& Case Study (1st Ed.). Jiangsu: Phoenix Science Press.

[10] Yunyue Peng. (2021). An Overview Of The Chinese Sponge City Programme And Its Implementation In Wuhan. Wuhan

\section{Author Profile}

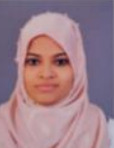

Shebina Hussain received B. Tech degree in Civil Engineering from Younus College of Engineering in 2018. Now, doing M. Plan degree in TKM College of Engineering, Kollam (2019-21 batch). 